\title{
Modified Electrodes with Polymers Based on Aniline and Thiophene: Characterization and Possible Use as a Sensor
}

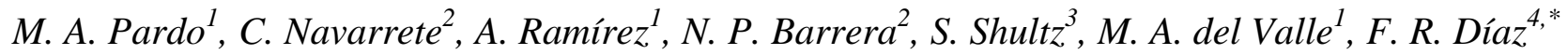 \\ ${ }^{1}$ Laboratorio de Electroquímica de Polímeros, LEP, Pontificia Universidad Católica de Chile, Av. V. \\ Mackenna 4860, 7820436 Macul, Santiago, Chile. \\ ${ }^{2}$ Laboratorio de Estructura de Proteínas de Membrana y Señalización, Departamento de Fisiología, \\ Facultad de Ciencias Biológicas, Pontificia Universidad Católica de Chile, Av. L. B. O’Higgins 340, \\ RM, Santiago, Chile. \\ ${ }^{3}$ Department of Chemistry and Biochemistry, University of NotreDame, 140D McCourtney Hall, \\ Notre Dame, IN 46556, USA \\ ${ }^{4}$ Departamento de Química y Biología, Facultad de Ciencias Naturales, Universidad de Atacama, \\ Copayapu 485, Copiapó, Chile. \\ *E-mail: mdvalle@uc.cl
}

doi: $10.20964 / 2017.05 .27$

Received: 19 January 2017 / Accepted: 12 March 2017 / Published: 12 April 2017

\begin{abstract}
A systematic steel and platinum electrodes were modified via drop-coating with polymers based on aniline and thiophene or aniline and 3-alkylthiophene previously synthesized and reported by us. Having in mind the possible applications of these materials, electrochemical (cyclic voltammetry, CV, in different electrolytic solutions), morphological and RAMAN characterization of the electrode|polymer systems was accomplished, using platinum or stainless steel discs of $0.07 \mathrm{~cm}^{2}$ geometric area as electrode substrates and poly[4-(2-thiophene)aniline], PTANI, poly [4-(3-methyl-2thiophene)-aniline], PTANIr1, and poly [4-(3-hexyl-2-thiophene)-aniline], PTANIr2 polymer coatings. A suspension of the respective polymer in tetrahydrofuran was filtered and drops of the soluble fraction of each polymer was deposited on the electrode surface, allowing the solvent to evaporate between each drop, until the whole electrode surface was coated. $n$ - and $p$-doping study was accomplished by $\mathrm{CV}$ in a $1.0 \cdot 10^{-3} \mathrm{~mol} \mathrm{~L}{ }^{-1} \mathrm{NaF}$ solution, using $0.05 \mathrm{~mol} \mathrm{~L}^{-1} \mathrm{LiClO}_{4}$ as supporting electrolyte. Thus, it was revealed that only the Pt|PTANI electrode displayed $p$-doping process, so it may be tried for anions removal or as an analytical sensor for this kind of species. Instead, PTANIr1 and PTANIr2 could be suggested as fluorescence sensors, while the absence of $p$ - and $n$-doping processes of the PTANIr2 system on steel and platinum electrodes, makes it a good candidate for metallic corrosion inhibition, since it is highly stable towards potential changes without damaging the deposited polymeric film.
\end{abstract}


Keywords: modified electrodes; polyaniline; polythiophene; poly[4-(2-thiophen)-aniline]; poly[4-(3metyl-2-tiophen)-aniline]; poly[4-(3-hexyl-2-tiophen)-aniline].

\section{$\underline{\text { FULL TEXT }}$}

(C) 2017 The Authors. Published by ESG (www.electrochemsci.org). This article is an open access article distributed under the terms and conditions of the Creative Commons Attribution license (http://creativecommons.org/licenses/by/4.0/). 